\title{
The effects of acute and chronic administration of $n-6$ and $n-3$ polyunsaturated fatty acids on ethanol-induced gastric haemorrhage in rats
}

\author{
BY B. HUNTER, G. S. A. MCDONALD AND M. J. GIBNEY* \\ Division of Nutritional Sciences, Department of Clinical Medicine and Department of Pathology, \\ Trinity College Medical School, St James' Hospital, Dublin 8, Republic of Ireland
}

(Received 20 December 1990 - Accepted 5 July 1991)

\begin{abstract}
Female weanling rats in three equal groups $(n$ 12) were given orally by intubation $1 \mathrm{ml}$ micellar solution of taurocholic aicd $(10 \mathrm{mM})$ and either arachidonic acid $(20: 4 n-6)$, linoleic acid $(18: 2 n-6)$ or eicosapentaenoic acid $(20: 5 n-3)$ at a concentration of $120 \mathrm{~mm}$. After $1 \mathrm{~h}$ the rats were given intragastrically $2 \mathrm{ml}$ absolute ethanol and were killed $1 \mathrm{~h}$ later. Rats given oral 20:4 n-6 showed a significant reduction $(P<0.05)$ in the extent $(\%)$ of gastric mucosal haemorrhage compared with either the rats given $20: 5 n-3$ or $18: 2 n-6(8.3$ (SD 7.3), 23.2 (SD 10.4) and 21.4 (SD 10.4) respectively. In a second experiment, four equal groups $(n$ 12) of female Wistar rats were fed for 5 weeks on either a control diet of standard laboratory rat food, or the same diet enriched with either maize oil or fish oil or butterfat at a level of $100 \mathrm{~g} / \mathrm{kg}$. Following a $24 \mathrm{~h}$ fast the rats received an intragastric dose of $2 \mathrm{ml}$ ethanol and were killed $1 \mathrm{~h}$ later. Examination of the extent $(\%)$ of gastric lesion showed a significant reduction $(P<0.05)$ with the feeding of either maize oil or fish oil compared with the controls (12.2 (SD 8.2), 15.3 (SD 13.2) and 29.3 (SD 14.0) respectively). The butterfat diet was not significantly different from the control diet (23.8 (SD 8.1)).
\end{abstract}

Arachidonic acid: Fish oil: Gastric haemorrhage

There is as yet no readily available animal model for human gastric or duodenal ulcer. In the absence of such, a number of noxious agents have been used to induce gastric mucosal injury in rats including absolute ethanol, $0.6 \mathrm{M}$-hydrochloric acid, $0.2 \mathrm{M}$-sodium hydroxide, sodium chloride $(250 \mathrm{~g} / \mathrm{l})$ and aspirin (Robert et al. 1979). The potential of exogenously administered prostaglandins to exert a cytoprotective effect against these and other agents and procedures has also been widely studied (Robert et al. 1979; Hollander et al. 1982; Tarnawski et al. 1988). This cytoprotective effect is not mediated by inhibition of gastric $\mathrm{HCl}$ secretion since it operates at levels below the anti-secretory effect of prostaglandins and since neither antacids nor anti-secretory compounds are effective as cytoprotectors (Miller \& Jacobson, 1979). These authors have also shown that even those prostaglandins without an action on acid secretion have cytoprotective properties. The most popular mechanisms proposed for these cytoprotective prostaglandins centre on the increased secretion of both mucus and bicarbonate, on the maintenance of blood flow and on the stimulation of the sodium pump in gastric mucosal cells (Robert 1979; Tarnawski et al. 1988).

Since the prostaglandins are capable of mediating cytoprotection, several workers have examined the potential of the precursor fatty acid, arachidonic acid $(20: 4 n-6)$, in this respect. Hollander et al. (1982) showed that exogenous administration of $20: 4 n-6$ to rats

*For reprints. 
stimulated the synthesis of prostaglandins, $\mathrm{PGE}_{2}$ in particular, and significantly reduced ethanol-induced gastric haemorrhage in rats. Exogenously administered linoleic acid $(18: 2$ $n$-6) has also been reported to stimulate gastric prostaglandin $\mathrm{PGE}_{2}$ production (Grant et al. 1988) and to protect against ethanol injury of rat gastric mucosa (Tarnawski et al. 1985).

Surprisingly little attention has been directed towards the longer-term effects of dietary oils rich in the $n-6$ polyunsaturated fatty acids (PUFA) on rat gastric cytoprotection. Given the opposing effects of oils rich in either the $n-6$ or $n-3$ PUFA on the development of circulatory disease (Bolton-Smith et al. 1988), the potential of the latter (fish oil) to exert an effect, via blood flow changes in mesenteric microvessels, requires attention. The present study set out to examine the relative cytoprotective effects of the $n-6$ PUFA $20: 4 n-6$ and $18: 2 n-6$ and the main $n-3$ PUFA eicosapentaenoic acid (20:5n-3), acutely administered, in protecting against ethanol-induced gastric injury in rats. The study also compared the effects of chronic feeding of the $n$-6-rich PUFA maize oil and the $n$ - 3 PUFA fish oil with both a low-fat control diet and with a high-fat diet rich in saturated fatty acids (butterfat) in this model.

\section{MATERIALS AND METHODS}

Weanling female Wistar rats $(50-100 \mathrm{~g})$ were used for the study. All animals were maintained on a standard laboratory diet before the start of the experiment. For the chronic study four groups of twelve rats each were fed for 5 weeks on a standard laboratory rat diet (Red Mills, Kilkenny) enriched with $100 \mathrm{~g} / \mathrm{kg}$ of either fish oil (Maxepa; Seven Seas Ltd, Hull), maize oil or butterfat. The oils were dissolved in diethyl ether and dispersed evenly over the feed pellets which were subsequently dried under nitrogen. The fourth group of rats was given the low-fat control diet consisting of the standard laboratory diet similarly treated with fat-free diethyl ether. All diets were offered ad lib. for 5 weeks and the diets presented fresh each day from frozen portions to minimize oxidative damage (Bolton-Smith et al. 1988). In the acute study the three groups of twelve rats were maintained on the standard laboratory rat diet for 5 weeks. At $1 \mathrm{~h}$ before the intubation with ethanol to induce the gastric haemorrhage, the rats in the acute study were given orally $1 \mathrm{ml}$ of a micellar solution containing $10 \mathrm{~mm}$-taurocholic acid and $120 \mathrm{~mm}$-eicosapentaenoic acid (20:5n-3), -linoleic acid (18:2n-6) or -arachidonic acid $(20: 4 n-6)$. The latter two fatty acids were obtained from Sigma (St Louis, USA) while the former was prepared from an ethyl ester of 20:5n-3 (Mochida, Tokyo, Japan) by hydrolysis under ethanolic potassium hydroxide $(50 \mathrm{~g} / \mathrm{l})$ for $12 \mathrm{~min}$ at $65^{\circ}$ under $\mathrm{N}_{2}$ in the dark. The saponified material was extracted in water followed by chloroform-methanol $(2: 1, \mathrm{v} / \mathrm{v})$. The material was identified as pure free fatty acid by thin-layer chromatography and the purity of the $20: 5$ $n-3$ confirmed by gas-liquid chromatography. The ethanol-induced gastric haemorrhage was achieved in both the chronic and acute study by an oral dose of $2 \mathrm{ml}$ absolute ethanol. The gastric haemorrhage was induced following a $24 \mathrm{~h}$ fast in both the chronic and the acute study and $1 \mathrm{~h}$ post intubation with fatty acids in the chronic study. Three control groups $(n 4)$ were orally dosed with the fatty acids and $1 \mathrm{~h}$ later with $2 \mathrm{ml}$ normal saline $(9 \mathrm{~g} \mathrm{NaCl} / 1)$ to assess possible uptake of fatty acids by the gastric mucosal cells and to serve as an ethanol control.

At $1 \mathrm{~h}$ after the ethanol or saline dose the animals were anaesthetized, killed by cardiac puncture and their stomach removed for gross examination of the area for haemorrhagic lesions and for microscopic evaluation of histological changes. The stomach was opened along the line of greater curvature and thoroughly rinsed with normal saline. The total area of the stomach and the total area lesioned were marked on a transparent grid with $1 \mathrm{~mm}^{2}$ markings which was overlaid on the stomach. The stomachs were then placed in formalin 
Table 1. Chronic effects of dietary fat source on the phospholipid fatty acid composition ( $\mathrm{mol} / 100 \mathrm{~mol}$ ) of rat gastric epithelium*

(Mean values with their pooled standard errors)

\begin{tabular}{|c|c|c|c|c|c|c|}
\hline Dictary fat ... & Control & Fish oil & Maize oil & Butterfat & $\begin{array}{c}\text { Pooled } \\
\text { SEM }\end{array}$ & $\begin{array}{c}\text { Statistical } \\
\text { significance } \\
P=\end{array}$ \\
\hline $16: 0$ & $28 \cdot 3^{a b)}$ & $30-5^{\mathrm{a}}$ & $24 \cdot 2^{h}$ & $25 \cdot 0^{\mathrm{b}}$ & 1.06 & $0 \cdot 004$ \\
\hline $18: 0$ & $10 \cdot 6^{\mathrm{a}}$ & $11 \cdot 8^{\mathrm{ab}}$ & $14 \cdot 2^{b}$ & $10 \cdot 3^{a}$ & $1 \cdot 24$ & 0.073 \\
\hline $16: 1$ & $1 \cdot 0^{\mathrm{a}}$ & $1 \cdot 9^{\mathrm{t}}$ & $0.9^{\mathrm{a}}$ & $1 \cdot 2^{a}$ & $0 \cdot 16$ & 0.003 \\
\hline $18: 1$ & $23 \cdot 2^{a}$ & $21.9^{a}$ & $19 \cdot 6^{\mathrm{b}}$ & $29 \cdot 9^{\prime \prime}$ & 0.66 & 0.003 \\
\hline $18: 2 n-6$ & $18 \cdot 0^{\mathrm{a}}$ & $14.9^{b}$ & $23 \cdot 1^{e}$ & $15 \cdot 9^{\prime \prime}$ & 0.77 & 0.000 \\
\hline $18: 3 n-3$ & $1 \cdot 0^{n \text {th }}$ & $1 \cdot 2^{1}$ & $0.8^{\mathrm{b}}$ & $0 \cdot 8^{\prime \prime}$ & $1 \cdot 11$ & 0.021 \\
\hline $20: 4 n-6$ & $15 \cdot 5^{\text {a }}$ & $7 \cdot 1^{13}$ & $14 \cdot 6^{a}$ & $13 \cdot 1^{a}$ & 0.44 & $0 \cdot 000$ \\
\hline $20: 5 n-3$ & $0.7^{\mathrm{a}}$ & $6 \cdot 6^{11}$ & $0 \cdot 5^{\mathrm{a}}$ & $1 \cdot 1^{\mathrm{a}}$ & 0.27 & 0.000 \\
\hline $22: 6 n-3$ & $0 \cdot 9^{\mathrm{a}}$ & $2 \cdot 2^{b}$ & $1 \cdot 1^{\mathrm{a}}$ & $1 \cdot 1^{\mathrm{a}}$ & $0 \cdot 16$ & 0.000 \\
\hline
\end{tabular}

a.b, Mean values for a given fatty acid with unlike superscript letters were significantly different $(P<0 \cdot 05)$.

* For details of diets and procedures, see pp. 502-503.

for histological examination. Stomachs from the control animals which had received the saline dose were similarly treated with the exception that the epithelial cells were removed by gentle scraping for subsequent lipid analysis.

The cells were washed in saline and the lipids extracted in $2 \mathrm{ml}$ chloroform-methanol $(2: 1 ; \mathrm{v} / \mathrm{v})$ followed by $2 \mathrm{ml}$ chloroform alone. All organic solvents used in the study contained butylated hydroxytoluene $(0 \cdot 1 \mathrm{~g} / 1)$ as an antioxidant. Phospholipids were isolated by thin-layer chromatography using light petroleum (b.p. $40-60^{\circ}$ )-diethyl ether-formic acid $(80: 20: 2$, by vol.). Fatty acid methyl esters were synthesized using sodium methoxide and the fatty acid composition determined by gas-liquid chromatography as previously described (Kearney et al. 1989).

The data were analysed by analysis of variance and, where indicated by the $F$ test, significant differences between means were determined using the least significance difference test.

\section{RESULTS}

The effects of a 5-week intake of diets containing $100 \mathrm{~g}$ fish oil, maize oil or butterfat $/ \mathrm{kg}$ on the phospholipid fatty acid composition of rat gastric mucosal cells is given in Table 1 and the mean values compared with those of a low-fat control diet. The fish-oil diet significantly increased the levels of 16:1 n-9, 20:5n-3 and 22:6n-3 and significantly decreased the levels of 18:1 n-9, 18:2 n-6 and 20:4 n-6 $(P<0.05)$. The maize-oil diet significantly increased the levels of $18: 0$ and $18: 2 n-6(P<0.05)$ and significantly reduced the levels of $18: 1 n-9(P<0 \cdot 05)$. The butterfat diet led to a significant increase in 18:1 $n-9$ and a significant decrease in $18: 2 n-6(P<0.05)$. Thus, the chronic administration of a dietary fat tended to influence fatty acid composition along the lines predictable from the fatty acid composition of the fat fed.

The effects of the acute administration of $20: 5 n-3,20: 4 n-6$ and $18: 2 n-6$ on rat gastric mucosal cell phospholipid fatty acids are given in Table 2 . There were no significant treatment effects insofar as the acute administration of a particular fatty acid did not lead to an elevation of that fatty acid in mucosal phospholipids. The significant differences otherwise noted were small, particularly in relation to those fatty acids involved in eicosanoid metabolism (20:4 n-6 and 20:5n-3). 
Table 2. Acute effects of intragastric intubation with free eicosapentaenoic acid, arachidonic acid and linoleic acid on the fatty acid composition ( $\mathrm{mol} / 100 \mathrm{~mol}$ ) of rat gastric epithelial cell phospholipids*

(Mean values with their pooled standard errors)

\begin{tabular}{lccccc}
\hline Fatty acid & $\begin{array}{c}\text { Eicosapentaenoic } \\
\text { acid } \\
\text { administered }\end{array}$ & $\begin{array}{c}\text { Arachidonic } \\
\text { acid } \\
(20: 5 n-3)\end{array}$ & $\begin{array}{c}\text { Linoleic } \\
\text { acid } \\
(20: 4 n-6)\end{array}$ & $\begin{array}{c}\text { Pooled } \\
(18: 2 n-6)\end{array}$ & $\begin{array}{c}\text { Statistical } \\
\text { significance : } \\
P=\end{array}$ \\
\hline $16: 0$ & $25 \cdot 1^{\mathrm{a}}$ & $27 \cdot 2^{\mathrm{b}}$ & $27 \cdot 9^{\mathrm{b}}$ & $0 \cdot 64$ & $0 \cdot 043$ \\
$18: 0$ & $10 \cdot 0^{\mathrm{a}}$ & $12 \cdot 5^{\mathrm{b}}$ & $11 \cdot 1^{\mathrm{a}}$ & $0 \cdot 50$ & $0 \cdot 023$ \\
$16: 1$ & $1 \cdot 2^{\mathrm{b}}$ & $1 \cdot 7^{\mathrm{b}}$ & $1 \cdot 2$ & $0 \cdot 23$ & $0 \cdot 398$ \\
$18: 1$ & $23 \cdot 3$ & $25 \cdot 7$ & $25 \cdot 1$ & $0 \cdot 80$ & $0 \cdot 147$ \\
$18: 2 n-6$ & $21 \cdot 3^{\mathrm{a}}$ & $15 \cdot 2^{\mathrm{b}}$ & $17 \cdot 5^{\mathrm{b}}$ & $0 \cdot 30$ & $0 \cdot 000$ \\
$18: 3 n-3$ & $0 \cdot 9^{\mathrm{b}}$ & $0 \cdot 8^{\mathrm{b}}$ & $0 \cdot 7$ & $0 \cdot 97$ & $0 \cdot 071$ \\
$20: 4 n-6$ & $15 \cdot 7^{\mathrm{a}}$ & $14 \cdot 3^{\mathrm{a}}$ & $12 \cdot 9^{\mathrm{b}}$ & $0 \cdot 51$ & $0 \cdot 011$ \\
$20: 5 n-3$ & $0 \cdot 6^{\mathrm{a}}$ & $0 \cdot 6^{\mathrm{a}}$ & $0 \cdot 8^{\mathrm{b}}$ & $0 \cdot 05$ & $0 \cdot 034$ \\
$22: 6 n-3$ & $1 \cdot 0^{\mathrm{b}}$ & $1 \cdot 3$ & $1 \cdot 1$ & $0 \cdot 11$ & $0 \cdot 163$ \\
\hline
\end{tabular}

${ }^{\mathrm{a}, \mathrm{b}}$ Mean values for a given fatty acid with unlike superscript letters were significantly different $(P<0 \cdot 05)$

* For details of diets and procedures, see pp. 502-503.

The effects of chronic and acute fat intake on ethanol-induced gastric haemorrhage in the rat are given in Table 3. In the chronic study the maize-oil and fish-oil diets led to a significant fall in the extent of the stomach lesion $(P<0.05)$. In the acute study the intubation with 20:4n-6 before administration of ethanol led to a significant decline in the area of stomach lesioned compared with rats given oral $20: 5 n-3$ or $18: 2 n-6(P<0.05)$.

Histologically the haemorrhagic mucosal lesions showed loss of surface epithelium and of crypt epithelium, the latter extending for varying degrees of depth. There was separation and disarray of surviving crypt epithelial cells. Mucosal congestion and haemorrhage were present. In some sections there was submucosal oedema and occasional focal haemorrhage in the vicinity of blood vessels. A very slight infiltrate of inflammatory cells was present immediately beneath the mucosa in a few sections.

\section{DISCUSSION}

In the last few years a series of papers have been published on the effect of $n-3$ and $n-6$ PUFA on rat gastric ulceration. The prostaglandin precursor $20: 4 n-6$, acutely administered to rats, is clearly protective against ethanol-induced gastric injury. This is evident from the present study and from the findings of Hollander et al. (1982). The acute effects of 18:2 $n-6$, similarly administered, did not show comparable effects in the present study which contrasts with the findings of Tarnawski et al. (1985). These authors, in a preliminary communication, did show that acutely administered 18:2 n-6 reduced the severity of ethanol injury in rats. However, the details are insufficient to discern when exactly the cytoprotective effect emerged or, indeed, the degree of cytoprotection. The interpretation of the present study is that, whereas exogenous 20:4n-6 provides an immediate substrate for eicosanoid synthesis which might account for the observed cytoprotective effect, the exogenous 18:2 n-6 would require elongation and desaturation by mucosal cells to achieve the same effect which would not be evident within the $1 \mathrm{~h}$ of study.

The effects of the $n$-3 PUFA on eicosanoid metabolism have generally been studied following chronic ingestion, allowing phospholipid 20:5n-3 levels to achieve a steady-state (Croft et al. 1984). The lack of effect of acutely administered 20:5 n-3 observed in the 
Table 3. Effects of chronic intakes of dietary fats and acute intakes of fatty acids on ethanol-induced haemorrhage* $\%$ with stomach lesions)

(Mean values with their pooled standard errors)

$\begin{array}{lc}\text { Chronic study }(n \text { 12) } & \\ \text { Control } & 29 \cdot 3^{\mathrm{a}} \\ \text { Fish oil } & 15 \cdot 3^{\mathrm{b}} \\ \text { Maize oil } & 12 \cdot 2^{\mathrm{b}} \\ \text { Butterfat } & 23 \cdot 8^{\mathrm{a}} \\ \text { SEM } & 3 \cdot 24 \\ \text { Statistical significance: } P= & 0 \cdot 002 \\ \text { Acute study }(n \text { 12) } & \\ \text { Eicosapentaenoic acid }(20: 5 n-3) & 23 \cdot 2^{\mathrm{a}} \\ \text { Arachidonic acid }(20: 4 n-6) & 8 \cdot 3^{\mathrm{b}} \\ \text { Linoleic acid }(18: 2 n-6) & 21 \cdot 4^{\mathrm{a}} \\ \text { SEM } & 2 \cdot 74 \\ \text { Statistical significance: } P= & 0 \cdot 000\end{array}$

\footnotetext{
${ }^{a, b}$ Mean values with unlike superscript letters, in either the chronic or acute study, were significantly different $(P<0.05)$.

* For details of diets and procedures, see pp. 502-503.
}

present study and the mucosal phospholipid fatty acid data would indicate that this uptake of 20:5n-3 into mucosal cell phospholipids did not occur in the hour between fatty acid and ethanol administration. However, this contrasts directly with the findings of Leung (1988) who noted a significant effect of fish oil (as opposed to free 20:5n-3) in reducing ethanol-induced gastric haemorrhage in rats. The higher the dose of fish oil the greater was the protection, and the longer the time-lapse between fish-oil dosing and ethanol injury the smaller was the degree of protection. Because this author did not include a control oil, it remains probable that the protective effect was a physical one. Thus, the balance of evidence supports the view that of the three fatty acids, 20:4n-6, 18:2n-6 and 20:5n-3, only the first is cytoprotective when acutely administered.

Several groups have examined the chronic effects of dietary fats on ethanol-induced gastric haemorrhage. Faust et al. (1989) fed rats for 4 weeks on either a low-fat control diet or the same diet enriched with $100 \mathrm{~g} / \mathrm{kg}$ of either maize oil or fish oil. The latter exerted a significant cytoprotective effect against ethanol injury compared with either of the other two diets. The mode of injury was, however, quite different from that used originally by Hollander et al. (1982) on which the design of the present study was based. Faust et al. (1989) used a preliminary dose with a mild ethanol irritant $(150 \mathrm{ml} / \mathrm{l})$ followed $15 \mathrm{~min}$ later by the more substantive irritant of absolute ethanol. The authors provide findings to show that this mechanism induces an 'adaptive protection'. Direct comparison with the present study is, therefore, difficult. However, both studies show that the chronic administration of fish oil reduces ethanol-induced gastric injury in rats, albeit to different degrees. The studies differ in their findings with respect to maize oil which was not cytoprotective in the study of Faust et al. (1989) and clearly cytoprotective in the present study. This latter finding tends to be supported by the findings of Mosnier et al. (1990). These authors fed rats for 3 weeks on diets containing either no added fat or $50 \mathrm{~g}$ supplements of maize oil or fish oil $/ \mathrm{kg}$. They induced gastric lesions using ethanol $(400 \mathrm{ml} / 1)$. Thus, their study differed from the present one in having a slightly shorter time-period ( $3 v .4$ weeks), a lower level of dietary oil $(50 v .100 \mathrm{~g} / \mathrm{kg})$ and a milder ethanol irritant $(400 v .1000 \mathrm{ml} / \mathrm{l})$. Nonetheless, their findings showed that both fish oil and maize oil led to a significant reduction in the number of injured rats ( 12.5 and $45 \%$ respectively) compared with rats given the low-fat 
control diet $(87 \%)$. Whilst the results are expressed differently in the two studies (\% rats injured $v . \%$ area lesioned), the findings confirm those of Faust et al. (1989) that fish-oil feeding is cytoprotective in this model and support the finding that maize oil is also cytoprotective. Further supportive evidence of a cytoprotective effect of maize oil in gastric lesions is available from the findings of Schepp et al. (1988) that chronic ingestion of 18:2 $n-6$, the main fatty acid in maize oil, is cytoprotective in a different model for inducing ulcers in rats, i.e. the cold-restraint model. The present study, which included a highsaturated-fat diet which did not differ from controls in the degree of injury, shows that whatever effect is ascribed to maize oil is not due merely to the physical presence of lipid in the diet.

The present study showed a marked elevation in mucosal phospholipid $20: 5 n-3$ and a marked depression in 20:4n-6 in fish-oil-fed animals. Such effects are widely reported for other tissues in fish-oil-fed animals, and the consequent effects on eicosanoid synthesis can be predicted from the extensive literature on the subject. These would include a reduced synthesis of the 2-series of eicosanoids and an increased synthesis of the 3-series. The increased levels of $18: 2 n-6$ in the mucosal phospholipids of maize-oil-fed rats might provide the basis for an increased rate of endogenous synthesis of $\mathrm{C}_{20: 4}$ and an increased endogenous production rate of the 2 -series of prostaglandins in these animals. The findings of Grant et al. (1988) in humans show that chronic ingestion of maize oil augments gastric $\mathrm{PGE}_{2}$ production. The level of increase in eicosanoid production observed by these workers was, however, only three-fold, whereas Hollander et al. (1982) found that in rats the increase in $\mathrm{PGE}_{2}$ synthesis following acute loading with 20:4 n-6 was 5000-13000 fold. In light of these effects two hypotheses are proposed to explain the cytoprotective effects of the $n-6$ and $n-3$ oils. In the case of the $n-6$ oils it is proposed that an increased endogenous production of $\mathrm{PGE}_{2}$ exerts its cytoprotection in the same way that the acute administration of 20:4n-6 does. A variety of mechanisms, previously discussed, could be involved. In the case of the $n-3$ oils it is proposed that maintenance of mucosal blood flow and reduced inflammatory response are the protective mechanisms. $n-3$ oils give rise to increased synthesis of thromboxane $\mathrm{A}_{3}$, a weakly thrombotic eicosanoid, and to increased synthesis of $\mathrm{PGI}_{3}$, a strong anti-thrombotic and vasodilatory agent (Knapp et al. 1986). Mesenteric venule thrombosis lies at the heart of the mucosal injury induced by ethanol (Guth et al. 1984; Hawkey \& Rampton, 1985; Szabo et al. 1985; Gronbech et al. 1988; Oates \& Hakkinen, 1988). Concentrated ethanol rapidly causes necrosis of superficial mucosal cells and the release of vasoactive mediators by mast cells. This triggers a series of strong constrictions that rapidly progress from small mucosal venules to larger venules. This coincides with a strong arteriolar and arterial vasodilation and leads to the engorgement of mucosal capillaries, creating visible hyperaemia and ultimately mucosal haemorrhage. The histological findings of the present study are consistent with this pattern. The histological findings of haemorrhagic necrosis of mucosa with varying degrees of epithelial cell loss are similar to those described by others in acute alcohol-induced mucosal injury. No vascular injury was seen but the haemorrhage and occasional submucosal oedema and perivascular haemorrhage suggest that this was occurring at a submicroscopic level. The established capacity of 20:5n-3 to reduce the inflammatory response (Endres et al. 1989) and to sustain mucosal blood flow would seem an attractive basis on which to explain their cytoprotective effect in ethanol-induced gastric injury.

\section{REFERENCES}

Bolton-Smith, C., Gibney, M. J., Gallagher, P. J., Jewell, R. \& Hillier, K. (1988). Effect of polyunsaturated fatty acids of the $n-3$ and $n-6$ series on lipid composition and eicosanoid synthesis of platelets and aorta and on immunological induction of atherosclerosis in rabbits. Atherosclerosis $72,29-35$. 
Croft, K. D., Beilin, L. J., Vandongen, R. \& Mathews, E. (1984). Dietary modification of fatty acid and prostaglandin synthesis in the rat. Biochimica et Biophysica Acta 795, 196-207.

Endres, S., Ghorbani, R., Kelley, V. E., Georgillis, K., Lonnemann, G., van der Meer, J. W. M., Cannon, J. G., Rogers, T. S., Klempner, M. S., Weber, P. C., Schaefer, E. J., Wolff, S. M. \& Dinarello, C. A. (1989). The effect of dietary supplementation with n-3 polyunsaturated fatty acids on the synthesis of interleukin- 1 and tumour necrosis factor by mononuclear cells. New England Journal of Medicine 320, 265-271.

Faust, T. W., Redfern, J. S., Podolsky, I., Lee, E., Grundy, S. M. \& Feltman, M. (1989). Effects of aspirin on gastric mucosal prostaglandin $E_{2}$ and $F_{2 \alpha}$ content and on gastric mucosal injury in humans receiving fish oil or olive oil. Gastroenterology 98, 586-591.

Grant, H. W., Palmer, K. R., Kelly, R. W., Wilson, N. H. \& Misiewiez, J. J. (1988). Dietary linoleic acid, gastric acid and prostaglandin secretion. Gastroenterology 94, $944-959$.

Gronbech, J. E., Matre, K., Stangeland, L., Svanes, K. \& Yarhaug, J. E. (1988). Gastric mucosal repair in the cat: role of the hyperemic response to mucosal damage. Gastroenterology 95, 31 ]-320.

Guth, P. H., Paulsen, G. \& Nagata, H. (1984). Histologic and microcirculatory changes in alcohol induced gastric lesions in the rat: effect of prostaglandin cytoprotection. Gastroenterology 87, 1083-1090.

Hawkey, C. J. \& Rampton, D. S. (1985). Prostaglandins and the gastrointestinal mucosa: Are they important in its function, disease or treatment? Gastroenterology 89, 1162-1188.

Hollander, D., Tarnawski, A., Ivey, K. J., DeZeery, A., Zipser, R. D., McKensie, W. N. \& McFarland, W. D. (1982). Arachidonic acid protection of rat gastric mucosa against ethanol injury. Journal of Laboratory and Clinical Medicine 100, 7151-7154.

Kearney, J., Kennedy, N. P., Keeling, P. W. N., Keating, J. J., Grubb, L., Kennedy, M. K. \& Gibney, M. J. (1989). Dietary intakes and adipose tissue levels of linoleic acid in peptic ulcer disease. British Journal of Nutrition 62, 699-706.

Knapp, H. R., Reilly, I. A. G., Alessandrini, P. \& Fitzgerald, G. A. (1986). In vivo indexes of platelet and vascular function during fish oil administration in patients with atherosclerosis. New England Journal of Medicine 314, 937-942.

Leung, F. W. (1988). Fish oil protection against absolute ethanol induced gastric injury. Gastroenterology 94 , A257.

Miller, T. A. \& Jacobson, E. D. (1979). Progress report: Gastrointestinal cytoprotection by prostaglandins. Gut 20, 7587.

Mosnier, P., Delasalle, P., Metta, C., Rayssiguier, Y.\& Bommelaer, G. (1990). Effects of dietary fish oil on gastric surfactant fluidity protection against ethanol induced gastric mucosal injury in rats. Gastroenterology, 98. A423.

Oates, P. J. \& Hakkinen, J. P. (1988). Studies on the mechanism of ethanol-induced gastric damage in rats. Gastroenterology 94, 10-21.

Robert, A. (1979). Cytoprotection by prostaglandins. Gastroenterology 77, 761-767.

Robert, A., Nezamis, J. E., Lancaster, C. \& Hanchar, J. (1979). Cytoprotection by prostaglandins in rats Gastroenterology 77, 433-443.

Schepp, W., Steffen, B., Ruoff, H. J., Schusdziarra, V. \& Classen, M. (1988). Modulation of rat gastric mucosal prostaglandin E2 release by dietary linoleic acid: Effects on gastric acid secretion and stress induced mucosal damage. Gastroenterology 95, 18-25.

Szabo, S., Trier, J. S., Brown, A. \& Schnoor, J. (1985). Early vascular injury and increased vascular permeability in gastric mucosal injury caused by ethanol in the rat. Gastroenterology 88, 228-236.

Tarnawski, A., Brzozowski, T., Sarfeh, J., Krause, W. J., Ulich, T. R., Gergely, H. \& Hollander, D. (1988). Prostaglandin protection of human isolated gastric glands against indomethacin and ethanol injury. Journal of Clinical Investigation 81, 1081-1089.

Tarnawski, A., Hollander, D., Krause, W. J., Stachura, J., Zipser, R. D., Gegely, H. \& Dadufalza, V. (1985). Is linoleic acid (dietary essential fatty acid-EFA) cytoprotective for the gastric mucosa? Gastroenterology $\mathbf{8 8}, 1610$. 